Article

\title{
High-Performance Semi-Flexible Pavement Coating Material with the Microscopic Interface Optimization
}

\author{
Yinshan $X u^{1,2}$, Yingjun Jiang ${ }^{1, *}$, Jinshun $X \mathrm{Xe}^{3, *}, \mathrm{Xi}_{\mathrm{i}}$ Tong $^{4}$ and Yuanyuan Cheng ${ }^{2}$ \\ 1 School of Highway, Chang'an University, Xi'an 710064, China; xys0613@126.com \\ 2 Zhejiang Scientific Research Institute of Transport, Hangzhou 310039, China; cyy94cxy@163.com \\ 3 School of Civil Engineering and Architecture; Hubei University of Arts and Science, \\ Xiangyang 441053, China \\ 4 Jiashan Highway Administration, Jiashan 314100, China; 13586302008@126.com \\ * Correspondence: jyj@chd.edu.cn (Y.J.); jinshunx@163.com (J.X.)
}

Received: 14 February 2020; Accepted: 11 March 2020; Published: 13 March 2020

\begin{abstract}
This paper aims to optimize the asphalt-mortar interface characteristics of semi-flexible pavement coating material (SFPCM), three types of the interface modifiers, namely the silane coupling agent, carboxylated styrene-butadiene latex, and cationic emulsified asphalt, are selected to add into the cement mortar to optimize the asphalt-mortar interface. The microscopic characteristics of the asphalt-mortar interface and the macroscopic pavement performance of the SFPCM after the interface optimization are investigated to reveal the effect of interface modifiers and determine the best formula. Results show that: (1) The dry shrinkage of the cement mortar is increased with the increased dosage of the interface modifiers, while the strength is decreased accordingly; (2) the optimum dosages of the silane coupling agent, carboxylated styrene butadiene latex, and cationic emulsified asphalt are $0.5 \%, 10 \%$, and $5 \%$, respectively; (3) the microscopic asphalt-mortar interface characteristics of the SFPCM with different interface modifiers have significant differences; (4) the SFPCM with the cationic emulsified asphalt presents the best pavement performance, particularly the high-temperature stability. These results can be attributed to improve the pavement properties of SFPCM.
\end{abstract}

Keywords: semi-flexible pavement coating material; asphalt-mortar; interface modifiers; interface characteristics; pavement properties

\section{Introduction}

Semi-flexible pavement coating material (SFPCM), with the advantage of the flexibility of asphalt concrete pavement and the rigidity of cement concrete pavement materials, is a new kind of composite pavement material, which is made by pouring special cement mortar into the open porous asphalt mixture (void ratio is $20 \%$ 28\%) [1]. The asphalt concrete pavement forms the material strength through aggregate interlocking [2,3], but the SFPCM forms the material strength through mutual intercalation of aggregate and cement stone, which improves the ability of pavement to resist the load $[4,5]$. In addition, its high temperature stability and water damage resistance are superior to asphalt concrete pavement, and its shear resistance, fatigue resistance, and slip resistance are also superior to cement concrete pavement. At the same time, it has the characteristics of oil resistance, acid resistance, and easy coloring [6,7].

The semi-flexible pavement originated in France and was originally used for the pavement of the airport runway, showing good road performance [8]. Subsequently, Britain, the United States, the former Soviet Union, and other countries conducted research on SFPM, which proved that the pavement material can extend the service life of the pavement and has good high temperature 
stability [9]. Lin was the first to construct the SFP test road in 1986, and achieved good practical results [10]. Ling et al. conducted a pavement performance test of SFPM, and considered that the performance of SFPM was superior to those of ordinary asphalt pavements when the mix design of SFPM was appropriate [11]. Hassan et al. studied the effects of fly ash and silica fume on the performance of cement mortar, and concluded that the fly ash and silicon can improve the fluidity and strength of cement mortar for SFPM [12]. Moreover, the application of fly ash as the alternative mineral filler in asphalt mixtures was also studied, showing that the asphalt mixtures with fly ash present better rutting resistance and higher resilient modulus. [13,14].

After the cement grout is poured into the asphalt mixture, the pavement performance of the SFPM is affected by the bond strength of the cement-asphalt interface. Poor contact at the interface results in insufficient strength and poor deformation. Zhou analyzed the failure mode of SFPM, indicating that the damage of semi-flexible pavement usually occurs at the interface between cement and asphalt and the damage of cement itself [15]. Huang et al. believed that the low-temperature cracking resistance of SFP could be greatly improved by waste rubber powder, when the ways of injection differed, the effect varied [16]. Wang et al. studied the improvement of pavement performance of different flexible latex materials for SFPM, which indicated that the pavement performance of SFPCM was significantly improved by adding polymers [17]. Liu analyzed the influence of the phase change material on the road performance of semi-flexible pavement materials, which indicated that the phase change material can enhance the low temperature crack resistance of semi-flexible pavement materials, but reduce its high temperature stability and water stability [18].

In this study, the cement-asphalt interface is optimized by adding an interface optimizer to the cement mortar, and the cement test is used to determine the optimum blending amount of various interface optimizers. Based on laboratory experiments, the SFPCM with different interface optimizers were prepared to analyze the influence of different interface optimizers on the microstructure and macroscopic properties of semi-flexible materials.

\section{Materials}

\subsection{Cement Mortar}

The cement mortar used in this study is developed in our previous study [19], of which the technical indexes are listed in Table 1. The self-developed cement mortar presents a good fluidity, small shrinkage deformation, and high initial strength.

Table 1. Technical indexes of cement mortar.

\begin{tabular}{cccc}
\hline \multicolumn{2}{c}{ Technical Indexes } & Results & Test Standard [20] \\
\hline \multicolumn{2}{c}{ Fluidity (s) } & 12.7 & GB/T 0508-2005 \\
Compressive strength & 1 day & 17.03 & \\
$(\mathrm{MPa})$ & 3 days & 32.63 & GB/T 0506-2005 \\
& 7 days & 42.98 & \\
\hline \multirow{2}{*}{ Flexural strength(MPa) } & 28 days & 54.53 & \\
& 1 day & 1.30 & GB/T 0506-2005 \\
& 3 days & 5.10 & \\
\hline & 7 days & 5.80 & GB/T 0511-2005
\end{tabular}

\subsection{Asphalt Binder}

In the existing studies, Styrene-butadiene-styrene (SBS) modified asphalt binders and high-viscosity asphalt binders are widely used to prepare the matrix asphalt mixture (open-porous asphalt mixture), because of the advantages in toughness and tenacity compared to other asphalt binders. 
Moreover, the workable performance of SBS modified asphalt binder is superior to high-viscosity asphalt binder. Hence, SBS modified asphalt binder is adopted to prepare the matrix asphalt mixture in this study.

The classification of the SBS modified asphalt binder is PG76-22. Other technical indexes are listed in Table 2.

Table 2. Technical indexes of SBS modified asphalt binder.

\begin{tabular}{|c|c|c|c|}
\hline \multicolumn{2}{|c|}{ Technical Indexes } & Results & Test Standard [21] \\
\hline \multicolumn{2}{|c|}{ Penetration $\left(100 \mathrm{~g} .5 \mathrm{~s} .25^{\circ} \mathrm{C}\right)(0.1 \mathrm{~mm})$} & 50.5 & GB/T 0604-2011 \\
\hline \multicolumn{2}{|c|}{ Ductility $\left(5^{\circ} \mathrm{C}, 5 \mathrm{~cm} / \mathrm{min}\right)(\mathrm{cm})$} & 32 & GB/T 0605-2011 \\
\hline \multicolumn{2}{|c|}{ Softening point $\left({ }^{\circ} \mathrm{C}\right)$} & 75.6 & GB/T 0606-2011 \\
\hline \multicolumn{2}{|c|}{ Elastic recovery $\left(25^{\circ} \mathrm{C}\right)(\%)$} & 77 & GB/T 0662-2000 \\
\hline \multirow{3}{*}{$\begin{array}{l}\text { After rotating film oven } \\
\text { experiment (RTFOT) }\end{array}$} & Mass loss (\%) & 0.01 & GB/T 0610-2011 \\
\hline & Penetration ratio $\left(25^{\circ} \mathrm{C}\right)(\%)$ & 96.5 & GB/T 0604-2011 \\
\hline & Ductility $\left(5^{\circ} \mathrm{C}\right)(\mathrm{cm})$ & 18.2 & GB/T 0605-2011 \\
\hline
\end{tabular}

\subsection{Aggregates}

The coarse and fine aggregates are both manufactured by basalts. Their technical indexes are listed in Table 3.

Table 3. Technical indexes of aggregates.

\begin{tabular}{|c|c|c|c|}
\hline Materials & Detection Indexes & Results & Test Standard [22] \\
\hline \multirow{7}{*}{ Coarse aggregate } & Coarse aggregate crush value (9.5-13.2) (\%) & 13.5 & GB/T 0316-2005 \\
\hline & Los Angeles wear value $(\%)$ & 11.6 & GB/T 0317-2005 \\
\hline & Polishing value & 63 & GB/T 0321-2005 \\
\hline & Apparent relative density $\left(\mathrm{g} / \mathrm{cm}^{3}\right)$ & 2.881 & GB/T 0304-2005 \\
\hline & Gross volume relative density $\left(\mathrm{g} / \mathrm{cm}^{3}\right)$ & 2.855 & GB/T 0304-2005 \\
\hline & Water absorption rate $(\%)$ & 0.319 & GB/T 0304-2005 \\
\hline & Needle and flake (>9.5 mm) $(\%)$ & 2.2 & GB/T 0312-2005 \\
\hline \multirow{4}{*}{ Fine aggregate } & Apparent relative density $\left(\mathrm{g} / \mathrm{cm}^{3}\right)$ & 2.677 & GB/T 0328-2005 \\
\hline & Methylene blue adsorption value (g/kg) & 0.75 & GB/T 0349-2005 \\
\hline & Sand equivalent $(\%)$ & 75 & GB/T 0334-2005 \\
\hline & Angularity (s) & 35 & GB/T 0345-2005 \\
\hline
\end{tabular}

\subsection{Interface Modifier}

Three types of interface modifiers are selected in this study, including silane coupling agent, carboxylated styrene-butadiene latex, and cationic emulsified asphalt.

The silane coupling agent is a kind of organic silicon compound that contains two groups with different chemical properties in molecules. It can react with inorganic materials and organic materials at the same time, thereby improving material properties (research institute of highway ministry of transport. 2005). The Kh-550 silane coupling agent (aminopropyl triethoxysilane), produced by Nanjing chengong Organic Silicon Materials Co., Ltd., is adopted in this study. The technical indexes are shown in Table 4. 
Table 4. Silane coupling agent technical indicators.

\begin{tabular}{ccc}
\hline Project & Results & Test Standard [23] \\
\hline Melting point $\left({ }^{\circ} \mathrm{C}\right)$ & 70 & GB/T617-2006 \\
Boiling point $\left({ }^{\circ} \mathrm{C}\right)$ & 217 & GB/T616-2006 \\
Water-soluble & React & GB/T683-2006 \\
Refractive index & 1.421 & GB/T6488-2008 \\
Flash point $\left({ }^{\circ} \mathrm{C}\right)$ & 96 & GB/T1671-2008 \\
Density $\left(\mathrm{g} / \mathrm{cm}^{3}\right)$ & 0.942 & GB/T4472-2011 \\
\hline
\end{tabular}

The carboxylated styrene-butadiene latex is a copolymer formed by emulsion polymerization of butadiene and styrene with a small amount of carboxylic acid and other additives. It is a kind of milky white-water dispersion with blue-purple luster [24]. Carboxyl styrene-butadiene latex has a high proportion of styrene, high binding strength and conjunctival strength, and residual benzene monomer is very small, which is an environmentally friendly product. The carboxylated styrene-butadiene latex used in this study is produced by Shanghai Gaoqiao BASF, and its technical indicators are shown in Table 5 .

Table 5. Carboxyl styrene-butadiene latex technical indicators.

\begin{tabular}{ccc}
\hline Project & Results & Test Standard [25] \\
\hline Solid content & 49.64 & $\mathrm{SH} / \mathrm{T} 1154-2005$ \\
PH value & 6.53 & $\mathrm{SH} / \mathrm{T} 1150-2005$ \\
Viscosity $/ \%$ & 285 & $\mathrm{SH} / \mathrm{T} 1152-2005$ \\
Minimum film forming & 13 & $\mathrm{SH} / \mathrm{T} 1609-2005$ \\
temperature $/{ }^{\circ} \mathrm{C}$ & 18 & $\mathrm{SH} / \mathrm{T} \mathrm{1799-2006}$ \\
$\begin{array}{c}\text { Glass transition } \\
\text { temperature } /{ }^{\circ} \mathrm{C}\end{array}$ & & \\
\hline
\end{tabular}

Cationic emulsified asphalt is processed by a variety of surfactants and cationic shale inhibitors and a certain range of softening point of asphalt. The cationic emulsified asphalt will react with the cement hydration product after demulsification to form a composite structure product. Its technical indicators are shown in Table 6.

Table 6. Cationic emulsified asphalt technical indicators.

\begin{tabular}{|c|c|c|c|}
\hline \multicolumn{2}{|c|}{ Project } & Results & Test Standard [21] \\
\hline \multicolumn{2}{|c|}{ Emulsifying speed } & slow crack & GB/T 0658-1993 \\
\hline \multicolumn{2}{|c|}{ Particle charge } & cation & GB/T 0653-1993 \\
\hline \multicolumn{2}{|c|}{ Sieve residue $(1.18 \mathrm{~mm}) / \%$} & 0.06 & GB/T 0652-1993 \\
\hline \multicolumn{2}{|c|}{ Residue content $/ \%$} & 55.5 & GB/T 0651-1993 \\
\hline \multicolumn{2}{|c|}{ Residue solubility/\% } & 98.6 & GB/T 0607-2011 \\
\hline \multicolumn{2}{|c|}{ Residue penetration $\left(25^{\circ} \mathrm{C}\right) / \mathrm{mm}$} & 78.2 & GB/T 0604-2011 \\
\hline \multicolumn{2}{|c|}{ Residue ductility $\left(15^{\circ} \mathrm{C}\right) / \mathrm{cm}$} & 76.9 & GB/T 0605-2011 \\
\hline \multicolumn{2}{|c|}{ Mixing test with coarse and fine aggregate } & uniform & GB/T 0659-1993 \\
\hline \multirow{2}{*}{$\begin{array}{c}\text { Storage stability at room } \\
\text { temperature } / \%\end{array}$} & 1 day & 0.5 & \multirow{2}{*}{ GB/T 0656-1993 } \\
\hline & 5 days & 4.3 & \\
\hline
\end{tabular}

\section{Dosage of the Interface Optimizations}

The effects of various interface modifiers on the physical and mechanical properties of cement grout materials were studied based on the research results of cement grout materials in this paper, and the optimal dosage of different interface optimizers was determined by the fluidity, dry shrinkage, and compressive and flexural strength tests of cement. Table 7 shows the test results of different interface optimizer dosages. 
Table 7. Test result of silane coupling agent.

\begin{tabular}{cccccc}
\hline $\begin{array}{c}\text { Interface } \\
\text { Optimizer }\end{array}$ & Dosage & Fluidity (s) & \multicolumn{2}{c}{ 7d Strength (MPa) } & \multirow{2}{*}{$\begin{array}{c}\text { Dry Shrinkage } \\
\text { (\%) }\end{array}$} \\
\cline { 4 - 5 } $\begin{array}{c}\text { Cement grout } \\
\text { materials }\end{array}$ & 0 & 12.7 & Flexural & Compressive & \\
\hline Silane coupling & $0.25 \%$ & 5.80 & 42.98 & 0.1845 \\
agent & $0.50 \%$ & 13.3 & 4.79 & 34.65 & 0.1985 \\
& $0.75 \%$ & 12.1 & 5.46 & 36.85 & 0.2049 \\
\hline $\begin{array}{c}\text { Carboxyl } \\
\text { styrene-butadiene }\end{array}$ & $5 \%$ & 14.8 & 5.04 & 33.61 & 0.2133 \\
\hline latex & $10 \%$ & 13.5 & 6.02 & 25.70 & 0.1794 \\
\hline $\begin{array}{c}\text { Cationic } \\
\text { emulsified }\end{array}$ & $15 \%$ & 12.3 & 6.21 & 29.70 & 0.1662 \\
asphalt & $5 \%$ & 15.7 & 5.93 & 26.15 & 0.1614 \\
\hline
\end{tabular}

It can be seen from Table 7 that the properties of the cement grout are lowered when the silane coupling agent is added. Then, with the gradual increase of the amount of the silane coupling agent, the fluidity and the strength of the cement grouting first increases and then decreases, and the dry shrinkage deformation gradually increases. When the amount of the silane coupling agent is in the range of $0.25 \%$ to $0.5 \%$, the fluidity is reduced by $5 \%$, the flexural strength is increased by $21 \%$, and the compressive strength is increased by $8 \%$. The dry shrinkage of the grout increases regularly with the increase of the amount of silane coupling agent. When the amount of the silane coupling agent is $0.5 \%$, the performance of the cement grout is optimal.

The flexural strength of the cement grout increases with the addition of carboxylated styrene-butadiene latex, and the shrinkage deformation decreases. With the increase of the content of carboxylated styrene-butadiene latex, the fluidity of cement grouting first increased and then decreased, the flexural strength first increased and then decreased, and the compressive strength and dry shrinkage deformation decreased regularly. When the content of carboxylated styrene-butadiene latex is in the range of $5 \%-10 \%$, the grout has the lowest fluidity, the flexural strength is increased by $7 \%$, the compressive strength is reduced by $10 \%$, and the shrinkage rate is reduced by $10 \%$. This indicates that the incorporation of carboxylated styrene-butadiene latex can improve the dry shrinkage deformation of cement grout and improve the flexural strength. When the content of carboxylated styrene-butadiene latex is $10 \%$, the performance of the cement grout is optimal.

When the cationic emulsified asphalt is added, the strength of the cement grout is lowered, and the shrinkage deformation is reduced. With the increase of the amount of cationic emulsified asphalt, the fluidity of cement grouting first decreases and then increases, the flexural strength increases first and then decreases, the compressive strength decreases regularly, and the shrinkage rate increases regularly. When the amount of cationic emulsified asphalt is $5 \%$, the fluidity is reduced by $10 \%$, the flexural strength is increased by $13 \%$, the compressive strength is slightly reduced, and the shrinkage ratio is reduced by $5 \%$. This indicates that the incorporation of cationic emulsified asphalt can improve the dry shrinkage deformation of cement grout and improve the flexural strength. When the amount of cationic emulsified asphalt is $5 \%$, the performance of the cement grout is optimal.

The interface optimizer has a great influence on the physical and mechanical properties of the cement grout. Both cationic emulsified asphalt and carboxylated styrene-butadiene latex can reduce the compressive strength and dry shrinkage of the grout, while the addition of silane coupling agent has no obvious effect on the improvement of strength and shrinkage. The optimum dosage of the silane coupling agent was determined by analysis to be $0.5 \%$, the optimum content of the carboxylated styrene-butadiene latex was $10 \%$, and the optimum dosage of the cationic emulsified asphalt was $5 \%$. 


\section{Preparation of the Semi-Flexible Material with Micro-Interface Optimization}

\subsection{Matrix Asphalt Mixtures}

The aggregate gradation of the matrix asphalt mixtures is shown in Table 8 and Figure 1 . The void ratio of matrix asphalt mixtures is $25 \%$.

Table 8. Design gradation for base asphalt mixture.

\begin{tabular}{cccccccccccc}
\hline \multicolumn{2}{c}{ Sieve Size $(\mathbf{m m})$} & $\mathbf{1 6}$ & $\mathbf{1 3 . 2}$ & $\mathbf{9 . 5}$ & $\mathbf{4 . 7 5}$ & $\mathbf{2 . 3 6}$ & $\mathbf{1 . 1 8}$ & $\mathbf{0 . 6}$ & $\mathbf{0 . 3}$ & $\mathbf{0 . 1 5}$ & $\mathbf{0 . 0 7 5}$ \\
\hline \multirow{3}{*}{ Pass rate (\%) } & $\begin{array}{c}\text { Design gradation } \\
\text { Minimum specified }\end{array}$ & 100 & 95 & 18 & 12 & 10 & 8.5 & 8 & 6.5 & 6 & 4 \\
& $\begin{array}{c}\text { limits } \\
\text { Maximum specified } \\
\text { limits }\end{array}$ & 100 & 90 & 10 & 8 & 5 & 5 & 4 & 3 & 3 & 2 \\
& 100 & 26 & 16 & 15 & 12 & 12 & 10 & 9 & 6 \\
\hline
\end{tabular}

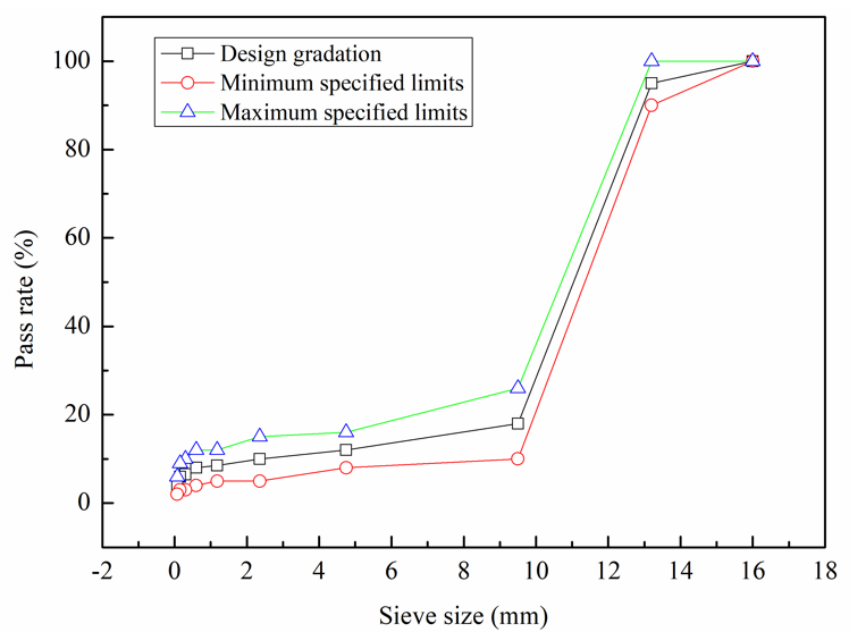

Figure 1. Gradation curve for base asphalt mixture.

The optimum asphalt content is determined by the Schellenberg Leakage test and the Kent-Berg Fly test. The void ratio and mechanical properties of the matrix asphalt mixtures is also verified via Marshall tests. The test results are shown in Table 9, indicating that the matrix asphalt mixture meets the design requirements and has a certain overall strength.

Table 9. Verification results of the mixture ratio of base asphalt mixture.

\begin{tabular}{cccc}
\hline $\begin{array}{c}\text { Optimum Asphalt } \\
\text { Content (\%) }\end{array}$ & $\begin{array}{c}\text { Measured Void Fraction } \\
\mathbf{( \% )}\end{array}$ & Stability (kN) & Flow Value (0.1 mm) \\
\hline 3.8 & 25.04 & 5.797 & 39.8 \\
\hline
\end{tabular}

\subsection{Preparation of Semi-Flexible Materials}

The preparation process of the semi-flexible material samples is as follows:

Step 1: Prepare the testing slabs $(L 300 \times W 300 \times H 50 \mathrm{~mm})$ of matrix asphalt mixture via rolling the compaction method at $160^{\circ} \mathrm{C}$ according to T0703-2011 [21]. These testing slabs must be cooled to lower than $50{ }^{\circ} \mathrm{C}$.

Step 2: Prepare the cement grouting material through mixing the cement mortar (Section 2.1) and interface optimizers for $5 \mathrm{~min}$ at room temperature.

Step 3: Pour the prepared cement grouting material into the prepared testing slab of the matrix asphalt mixture with the help of mini plate vibrator until the cement grouting material overflows. Scrape away redundant cement grouting material using the mini rubber scraper. Finally, the test sample of the semi-flexible material can be obtained after curing, as shown in Figure 2. 


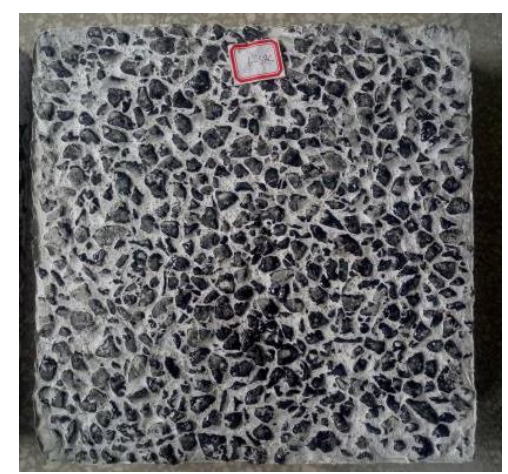

Figure 2. Prepared sample of semi-flexible material.

\section{Micro-Characteristics of Semi-Flexible Pavement Material with Interface Optimizer}

SEM electron microscopy was used to observe the texture structure of cement-asphalt interface in high performance semi-flexible materials from a microscopic point of view in this paper, and the influence of different interface optimizers on interface microscopicity was analyzed.

\subsection{Silane Coupling Agent}

Figure 3 is an electron microscopic scanning view of cement-asphalt interface modified by a silane coupling agent. The black part is asphalt and the light gray part is hardened cement grout in the figure. It can be seen in the figure that there is a coherent flat crack at the junction of cement and asphalt. When the crack is enlarged, it can be seen that the cement and the asphalt are connected together by a part of the convex products, and the crack between the two is deep. The surface of the cement is uneven and angular, and the surface of the asphalt is uneven at the interface. This indicates that the connection between the silane coupling agent-modified cement and the asphalt is unstable, and there is a long and continuous gap.

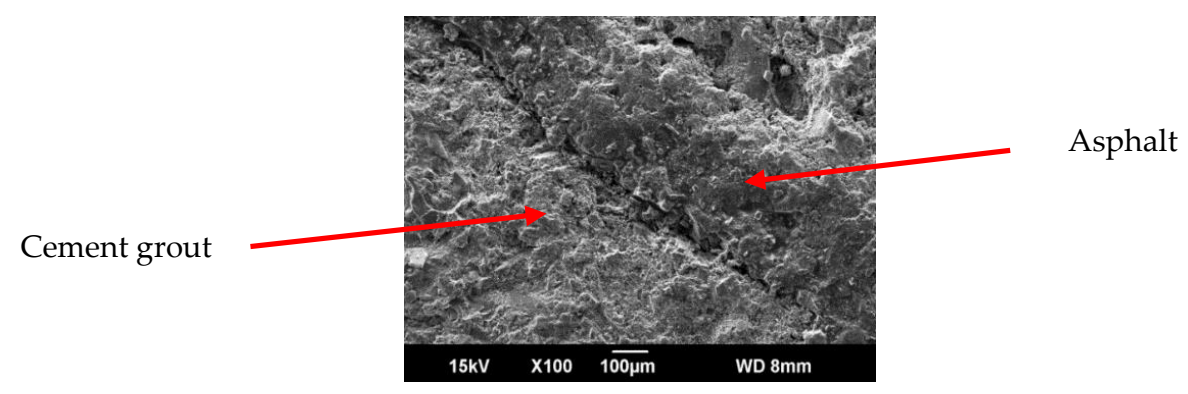

(a)

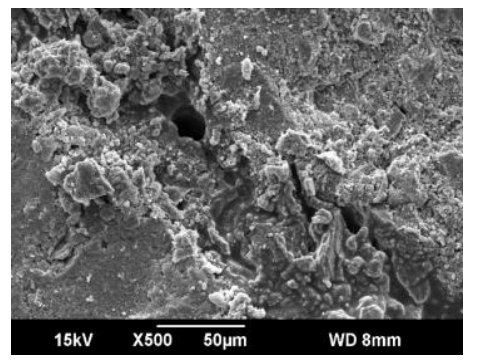

(b)

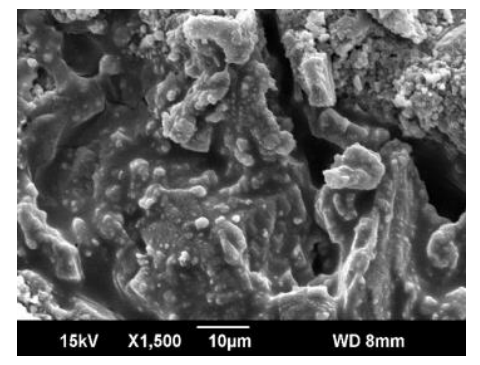

(c)

Figure 3. Microstructure of cement-asphalt interface modified by silane coupling agent with different sizes: (a) $100 \mu \mathrm{m}$; (b) $50 \mu \mathrm{m}$; (c) $10 \mu \mathrm{m}$. 


\subsection{Carboxyl Styrene-Butadiene Latex}

Figure 4 is an electron microscopic scanning view of cement-asphalt interface modified with carboxylated styrene-butadiene latex. It can be seen from the figure that the connection between cement and asphalt is relatively tight, and cracks appear in some locations. The surface of the cement is uneven, and some of the cement particles are covered with asphalt, which does not pierce the asphalt and forms a good connection with the asphalt. This indicates that the interface between the carboxylated styrene-butadiene latex modified cement and the asphalt is better, and the adhesion of the asphalt to the cement particles enhances the connection between the two.

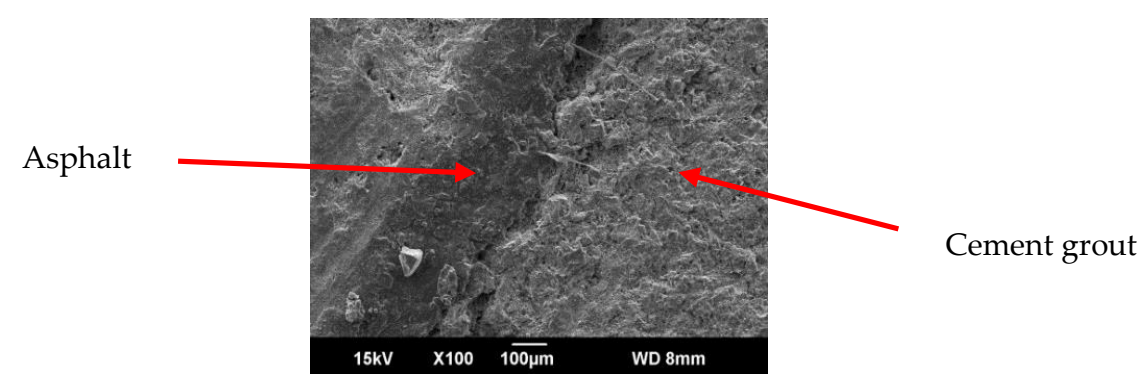

(a)

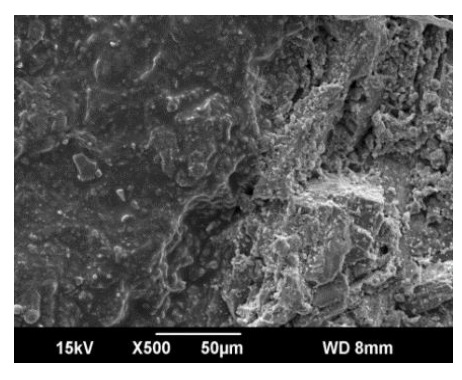

(b)

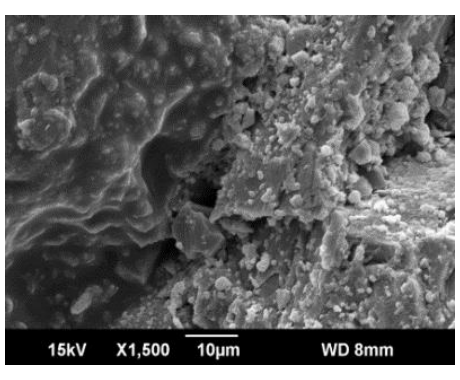

(c)

Figure 4. Microstructure of cement-asphalt interface modified by carboxyl styrene-butadiene latex with different sizes: (a) $100 \mu \mathrm{m}$; (b) $50 \mu \mathrm{m}$; (c) $10 \mu \mathrm{m}$.

\subsection{Cationic Emulsified Asphalt}

Figure 5 is an electron microscopic scanning diagram of emulsified asphalt modified cement-asphalt interface. It can be seen from the figure that the cement and the asphalt are closely connected, and the asphalt at the interface forms a whole with the cement, and no obvious cracks are generated. The cement surface is relatively flat, and the cement at the edge of the interface is wrapped with asphalt to form a good connection with the asphalt. This indicates that the cationic emulsified asphalt makes the cement and the asphalt at the interface merge with each other, the connection at the interface is integrated, and the stability at the interface is good. 


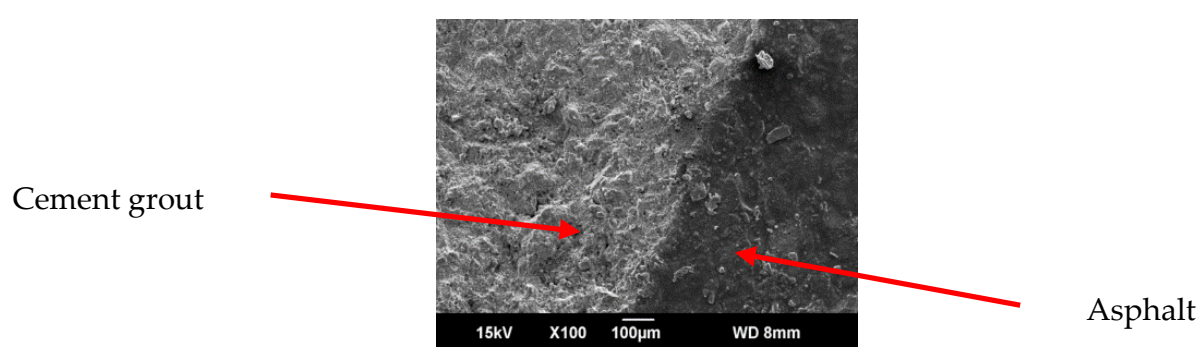

(a)

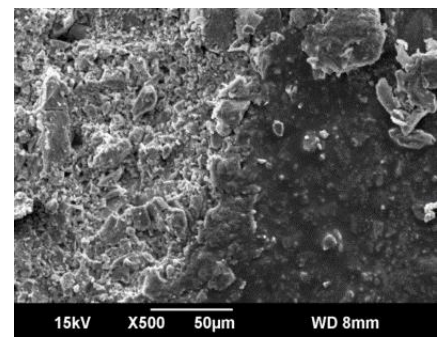

(b)

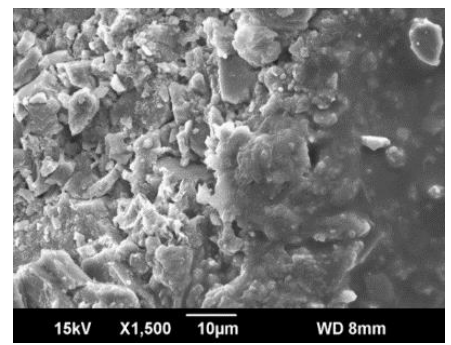

(c)

Figure 5. Microstructure of cement-asphalt interface modified by cationic emulsified asphalt with different sizes: (a) $100 \mu \mathrm{m}$; (b) $50 \mu \mathrm{m}$; (c) $10 \mu \mathrm{m}$.

It can be seen from the above analysis that the interface optimizer makes a large difference in the microstructure of the cement-asphalt interface. The interface of the cationic emulsified asphalt is more tightly connected, no obvious cracks are generated, and the cement surface is relatively flat; the interface of the carboxylated styrene-butadiene latex is tightly connected, and some micro-cracks are present, and the surface of the cement is uneven; the interface at the interface of the silane coupling agent is poorly connected, and there is a large continuous gap, and the surface of the cement is uneven and angular.

\section{Pavement Properties of the Semi-Flexible Material with Micro-Interface Optimization}

The macroscopic effect of interface optimizer on the road performance of semi-flexible materials is analyzed through laboratory tests in this paper. Since the semi-flexible material is based on the asphalt mixture and is poured into the cement grout, although it is a rigid-flexible material, it is generally biased toward the flexibility of the base asphalt mixture. Therefore, this study used the road performance evaluation method of asphalt mixture to study the effect of interface optimizer on semi-flexible materials, and the tests measured according to Standard Test Methods of Bitumen and Bituminous Mixtures for Highway Engineering (JTG E20—2011) [21].

\subsection{High-Temperature Stability}

Table 10 shows the results of high temperature rutting tests for different semi-flexible materials.

Table 10. Rutting test results.

\begin{tabular}{cccc}
\hline Interface Optimizer & $\begin{array}{c}\text { Dynamic Stability } \\
\text { (time/mm) }\end{array}$ & $\begin{array}{c}\mathbf{4 5} \mathbf{m i n} \text { Rutting Depth } \\
\mathbf{( m m})\end{array}$ & $\begin{array}{c}\mathbf{6 0} \text { min Rutting Depth } \\
(\mathbf{m m})\end{array}$ \\
\hline Cement grout materials & 13695.65 & 1.342 & 1.388 \\
$\begin{array}{c}\text { Silane coupling agent } \\
\text { Carboxyl }\end{array}$ & 16578.95 & 1.11 & 1.148 \\
$\begin{array}{c}\text { styrene-butadiene latex } \\
\text { Cationic emulsified } \\
\text { asphalt }\end{array}$ & 14318.18 & 1.06 & 1.104 \\
\hline
\end{tabular}


It can be seen from Table 10 that the dynamic stability of the high performance semi-flexible pavement material at $60^{\circ} \mathrm{C}$ is more than 10,000 times $/ \mathrm{mm}$, which is much larger than the conventional modified asphalt mixture, and the interface optimizer type has a greater influence on the high temperature performance of the semi-flexible material. The semi-flexible material incorporating cationic emulsified asphalt has the best high-temperature anti-rutting performance, and its dynamic stability is much larger than the other two interface optimizers, and the rutting depth is the smallest. The results show that the semi-flexible material has relatively high temperature stability. The incorporation of the interface optimizer can significantly improve the high temperature stability of the semi-flexible material [26], wherein the cationic emulsified asphalt has the most obvious lifting effect.

\subsection{Low-Temperature Crack Resistance}

Table 11 shows the results of low temperature bending tests for different high performance semi-flexible materials.

Table 11. Low-temperature bending test results.

\begin{tabular}{cccc}
\hline Interface Optimizer & Strain $(\boldsymbol{\mu \varepsilon})$ & Stress (MPa) & $\begin{array}{c}\text { Stiffness Modulus } \\
(\mathbf{M P a})\end{array}$ \\
\hline Cement grout materials & 1490.24 & 6.05 & 4059.75 \\
Silane coupling agent & 1826.725 & 7.17 & 3927.63 \\
$\begin{array}{c}\text { Carboxyl } \\
\text { styrene-butadiene latex } \\
\text { Cationic emulsified } \\
\text { asphalt }\end{array}$ & 1807.235 & 6.47 & 3579.72 \\
\hline
\end{tabular}

It can be seen from Table 11 that the stress and strain of the ordinary semi-flexible material at low temperature failure are low, however, the low-temperature crack resistance of the semi-flexible material is improved after the interface optimizer is incorporated. The semi-flexible material incorporating cationic emulsified asphalt has a low temperature failure strain increase of $43 \%$ and a stiffness modulus of $19 \%$, and the material has good low temperature crack resistance. The results show that the low temperature crack resistance of ordinary semi-flexible materials is poor. The incorporation of interface optimizer can significantly improve the low temperature crack resistance of semi-flexible materials, and the effect of cationic emulsified asphalt is most obvious.

\subsection{Water Stability}

Table 12 shows the results of freeze-thaw splitting tests for different high performance semi-flexible materials.

Table 12. Results of freeze-thaw splitting test.

\begin{tabular}{cccc}
\hline Interface Optimizer & $\begin{array}{c}\text { Pre-Freezing Strength } \\
\mathbf{( M P a )}\end{array}$ & $\begin{array}{c}\text { Post-Freezing Strength } \\
\mathbf{( M P a )}\end{array}$ & TSR (\%) \\
\hline Cement grout materials & 1.064 & 0.792 & 74.44 \\
Silane coupling agent & 1.442 & 1.179 & 81.76 \\
$\quad \begin{array}{c}\text { Carboxyl } \\
\text { styrene-butadiene latex } \\
\text { Cationic emulsified } \\
\text { asphalt }\end{array}$ & 1.078 & 0.843 & 78.20 \\
\hline
\end{tabular}

It can be seen from Table 12 that the high-performance semi-flexible material has a relatively large freeze-thaw splitting strength and good water stability. The splitting strength of the semi-flexible material increases with the addition of the interface optimizer. The high-performance semi-flexible material incorporating cationic emulsified asphalt has the highest freeze-thaw splitting strength and 
a TSR increase of $18 \%$. This indicates that the cation can significantly improve the water stability of the semi-flexible material, followed by the carboxylated styrene-butadiene latex. The results show that the semi-flexible material has good water stability, and its freeze-thaw split ratio is more than $70 \%$. The incorporation of an interface optimizer enhances the water stability of the semi-flexible material, wherein the high performance semi-flexible material incorporating the cationic emulsified asphalt is optimal in stability.

It can be known from the above analysis that the interface optimizer has a great influence on the performance of the semi-flexible material. The properties of high temperature rutting resistance, low temperature crack resistance, and water stability were improved after adding the interface optimizer, which indicated that the interface optimizer could improve the road performance of semi-flexible materials. Among the three kinds of interface optimizers, the emulsified asphalt has the greatest influence on the performance of the semi-flexible material, which indicates that the road performance of the high-performance semi-flexible material doped with the cationic emulsified asphalt is optimal.

\section{Conclusions}

The present study determined the optimum dosage of interface optimizers and investigated the effects of interface optimization on the micro-structure and macro-properties of SFPCM. The main conclusions are as follows:

(1) The physical and mechanical properties of the cement mortar are changed significantly with the addition of interface optimizers. The interface optimizers improve the dry shrinkage resistance but weaken the strength of cement mortar.

(2) In this study, the optimum dosage of the silane coupling agent, the carboxylated styrene-butadiene latex, and the cationic emulsified asphalt is $0.5 \%, 10 \%$, and $5 \%$, respectively.

(3) The cement-asphalt interface of semi-flexible materials will be modified obviously by interface optimizers, particularly the cationic emulsified asphalt. The cationic emulsified asphalt greatly improves the interfacial connection between cement and asphalt. The cement-asphalt interface is relatively flat and has no obvious cracks. Moreover, the modification effect of silane coupling agent is the worst.

(4) The proposed semi-flexible materials with interface optimization provide satisfactory high-temperature stability, low-temperature crack resistance, and water stability, particularly high-temperature stability, showing the positive effectiveness of interface optimizers. Particularly, the semi-flexible material modified by the cationic emulsified asphalt presents the best pavement performance.

The effects of interface optimization on fatigue resistance and slip resistance of SFPCM will be conducted in further studies.

Author Contributions: Conceptualization, Y.X., Y.J., J.X. and X.T.; Data curation, J.X. and Y.C.; Formal analysis, Y.X. and J.X.; Funding acquisition, Y.X., Y.J., J.X. and X.T.; Investigation, J.X., X.T. and Y.C.; Methodology, Y.J.; Writing-original draft, J.X.; Writing-review \& editing, Y.X., Y.J. and J.X. All authors have read and agreed to the published version of the manuscript.

Funding: This research was funded by the Natural Science Foundation of Zhejiang Province (grant number LQY19E080002), the Highway Technology Projects of Zhejiang Province (grant number 2018H25 and 2018H38), the Scientific Research of Central Colleges of China for Chang'an University (grant number 300102218205 and 300102218212), and the Doctoral Research Foundation of Hubei University of Arts and Science (grant number 2059084), to which the authors are very grateful.

Conflicts of Interest: The authors declare no conflict of interest.

\section{References}

1. Pei, J.Z.; Cai, J.; Zou, D.G.; Zhang, J.P.; Li, R.; Chen, X.F.; Jin, L. Design and performance validation of high-performance cement paste as a grouting material for semi-flexible pavement. Constr. Build. Mater. 2016, 126, 206-217. [CrossRef] 
2. Vavrik, W.R.; Carpente, S.H. Calculating air voids at specified number of gyrations in Superpave gyratory compactor. Transp. Res. Rec. 1998, 1630, 117-125. [CrossRef]

3. Polaczyk, P.; Huang, B.S.; Shu, X.; Gong, H.R. Investigation into locking point of asphalt mixtures utilizing Superpave and Marshall compactors. J. Mater. Civ. Eng. 2019, 31, 04019188. [CrossRef]

4. Wang, Y.J.; Guo, C.Y.; Tian, Y.F.; Wang, J.J. Design of mix proportion of cement mortar with high-performance composite semi-flexible pavement. Adv. Mater. Res. 2013, 64, 342-345. [CrossRef]

5. Gong, M.H.; Xiong, Z.J.; Chen, H.; Deng, C.; Chen, X.H.; Yang, J.; Zhu, H.R.; Hong, J.X. Evaluation on the cracking resistance of semi-flexible pavement mixture by laboratory research and field validation. Constr. Build. Mater. 2019, 207, 387-395. [CrossRef]

6. Zhang, J.P.; Cai, J.; Pei, J.Z.; Li, R.; Chen, X.F. Formulation and performance comparison of grouting materials for semiflexible pavement. Constr. Build. Mater. 2016, 115, 582-592. [CrossRef]

7. Koting, S.; Karim, M.R.; Mahmud, H.B.; Abdul, H.; Norjidah, A. Mechanical properties of cement-bitumen composite for semi-flexible pavement surfacing. Balt. J. Road. Bridge. E 2014, 9, 191-199. [CrossRef]

8. Bao, L. French New Pavement Standard Structure Manual; China Communications Press: Beijing, China, 1987.

9. Pelland, R.J.; Gould, J.S.; Mallick, R.B. Selecting a rut resistant hot mix asphalt for boston-logan international airport. In airfield pavements. Challenges and new technologies. Am. Soc. Civ. Eng. 2004, 390-408. [CrossRef]

10. Li, K. Study on the Applicability of Semi-Flexible Materials as Anti-Rutting Functional Layer of Asphalt Pavement. Ph.D. Thesis, South China University of Technology, Guangzhou, China, 2016.

11. Ling, T.Q.; Qian, D.; Dong, Y.Y.; Zhao, Z.J.; Li, C.Z. Application of rubber asphalt in filling semi-flexible pavement. J. Chang An Univ. 2009, 29, 24-27. [CrossRef]

12. Hassan, K.E.; Setyawan, A. Effect of cementitious grouts on the properties of semi-flexible bituminous pavements. In Proceedings of the 4th European Symposium on Performance of Bituminous and Hydraulic Materials in Pavements, Nottingham, UK, 11-12 April 2002.

13. Rongali, U.; Singh, G.; Chourasiya, A.; Jain, P.K. Laboratory performance of stone matrix asphalt containing composite of fly ash and plastic waste. Res. J. Agric. Anim. Sci. 2013, 72, 186-192.

14. Woszuk, A.; Bandura, L.; Franus, W. Fly ash as low cost and environmentally friendly filler and its effect on the properties of mix asphalt. J. Clean. Prod. 2019, 235, 493-502. [CrossRef]

15. Zhou, L. Temperature Adaptability and Failure Mode Analysis of Semi-Flexible Composite Pavement. Ph.D. Thesis, Chongqing Jiaotong University, Chongqing, China, 2016.

16. Yang, Y.; Ding, Q.; Huang, C.; Huang, S.L. Research on the low-temperature cracking resistance of semi-flezible pavement with waste rubber powder. In Proceedings of the Asphalt Rubber 2009 Conference, Nanjing, China, 2 November 2009.

17. Wang, D.Y.; Liang, X.Y.; Jiang, C.F.; Pan, Y.Z. Impact analysis of carboxyl latex on the performance of semi-flexible pavement using warm-mix technology. Constr. Build. Mater. 2018, 179, 566-575. [CrossRef]

18. Liu, B.J.; Liang, D. Effect of mass ratio of asphalt to cement on the properties of cement modified asphalt emulsion mortar. Constr. Build. Mater. 2017, 134, 39-43. [CrossRef]

19. Sun, Y.Z.; Cheng, Y.Y.; Ding, M.; Yuan, X.Z.; Wang, J.C. Research on properties of high-performance cement mortar for semi-flexible pavement. Adv. Mater. Sci. Eng. 2018, 4613074. [CrossRef]

20. Ministry of Transport of PRC. Test Methods of Cement and Concrete for Highway Engineering (JTG E30-2005); China Communications Press: Beijing, China, 2005.

21. Ministry of Transport of PRC. Standard Test Methods of Bitumen and Bituminous Mixtures for Highway Engineering (JTG E20-2011); China Communications Press: Beijing, China, 2011.

22. Ministry of Transport of PRC. Test Methods of Aggregate for Highway Engineering (JTG E42-2005); China Communications Press: Beijing, China, 2005.

23. Ministry of Industry and Information Technology of PRC. Unsaturated Silane Coupling Agent (HG/T 4894-2016); Ministry of Industry and Information Technology of PRC: Beijing, China, 2016.

24. Su, D.G.; He, J.; Zhang, J.F. Effect of silane coupling agent on the interface between asphalt and stone and cement mortar. J. South China Univ. Technol. 2007, 02, 112-115. 
25. AQSIQ. Synthetic Rubber Latex-Part 1: Carboxyl Styrene-Butadiene Rubber Latex (GB/T 25260.1-2010); China National Standardization Management Committee: Beijing, China, 2010.

26. Yi, Y.; Jiang, Y.J.; Li, Q.L.; Deng, C.Q.; Ji, X.P.; Xue, J.S. Development of super road heat-reflective coating and its field application. Coatings 2019, 9, 802. [CrossRef]

(C) 2020 by the authors. Licensee MDPI, Basel, Switzerland. This article is an open access article distributed under the terms and conditions of the Creative Commons Attribution (CC BY) license (http://creativecommons.org/licenses/by/4.0/). 